\title{
Bond strength of a universal bonding agent and other contemporary dental adhesives applied on enamel, dentin, composite, and porcelain
}

Cristina P Isolan ${ }^{1}$, Lisia L Valente ${ }^{1}$, Eliseu A Münchow ${ }^{1 *}$, Gabriela R Basso ${ }^{1}$, Alice H Pimentel ${ }^{2}$, Jülia K Schwantz², Andreza $V$ da Silva ${ }^{2}$ and Rafael R Moraes ${ }^{1,2}$

\author{
* Correspondence: \\ eliseumunchow@hotmail.com \\ ${ }^{1}$ Graduate Program of Dentistry, \\ School of Dentistry, Federal \\ University of Pelotas, Rua Gonçalves \\ Chaves, 457, Pelotas, RS 96015-560, \\ Brazil \\ Full list of author information is \\ available at the end of the article
}

\begin{abstract}
The aim of this study was to compare the bonding ability of a universal dental adhesive (Scotchbond Universal/SBU, 3 M ESPE) and other contemporary dental bonding agents applied to different substrates: enamel, dentin, resin composite, and porcelain. SBU was tested using both the etch-and-rinse/ER and self-etch/SE bonding approaches. The other adhesives tested were Scotchbond Multipurpose/SBMP (3 M ESPE), Single Bond 2/SB (3 M ESPE), and Clearfil SE Bond/CLSE (Kuraray). Specimens of each substrate were prepared for microtensile bond strength test/ $\mu$ TBS (dentin and composite) or shear/SBS test (enamel and porcelain). In composite and porcelain, negative (no treatment) and positive (silane + SB) control groups were tested. Data were analyzed using One-Way ANOVA and Tukey's test $(a=0.05)$. In enamel, SBU resulted in similar SBS ( $p \geq 0.458)$ compared to all other adhesives (SBMP $=19.0 \pm 10.2^{B}$; $\left.\mathrm{SB}=26.6 \pm 9.3^{\mathrm{A}} ; \mathrm{CLSE}=26.0 \pm 8.5^{\mathrm{A}} ; \mathrm{SBU}-\mathrm{SE}=23.5 \pm 8.4^{\mathrm{AB}} ; \mathrm{SBU}-\mathrm{ER}=22.6 \pm 9.9^{\mathrm{AB}}\right)$. In dentin, SBU showed similar results to all other materials ( $p \geq 0.123)$, except SB ( $p \leq 0.045)$, which showed the highest $\mu \mathrm{TBS}\left(\mathrm{SBMP}=35.4 \pm 10.5^{\mathrm{AB}} ; \mathrm{SB}=39.4 \pm 11.2^{\mathrm{A}} ; \mathrm{CLSE}=36.6 \pm 10.9^{\mathrm{AB}}\right.$; SB-SE $=28.1 \pm 13.7^{\mathrm{B}} ; \mathrm{SBU}-\mathrm{ER}=26.9 \pm 7.4^{\mathrm{B}}$ ). In resin composite, SBU and the positive control presented similar $\mu$ TBS $(p=0.963)$, and were higher than the negative control $(p \leq 0.001)$ $\left(\mathrm{SBU}=28.4 \pm 9.9^{\mathrm{A}}\right.$; positive control $=29.5 \pm 11.7^{\mathrm{A}}$; negative control $\left.=12.1 \pm 8.7^{\mathrm{B}}\right) . \mathrm{In}$ porcelain, SBU had higher SBS than the positive control $(p=0.001)$, which showed higher SBS $(p<0.001)$ than the negative control $\left(S B U=29.0 \pm 6.9^{A}\right.$; positive control = $21.0 \pm 7.0^{B}$; negative control $=5.3 \pm 2.7^{\complement}$ ). Equilibrium of adhesive and mixed failures occurred in dentin and resin composite, whereas a predominance of adhesive failures was observed in enamel and porcelain. In conclusion, the bonding ability of the universal adhesive was comparable to the other contemporary bonding agents tested, although it was dependent on the substrate evaluated. Universal adhesives seem to have potential applicability in adhesive dentistry.
\end{abstract}

Keywords: Adhesion; Composite resins; Glass ceramics; pH; Shear bond strength; Tensile bond strength

\section{Springer}

(c) 2014 Isolan et al.; licensee Springer. This is an Open Access article distributed under the terms of the Creative Commons Attribution License (http://creativecommons.org/licenses/by/4.0), which permits unrestricted use, distribution, and reproduction in any medium, provided the original work is properly credited. 


\section{Background}

Adhesive bonding in dentistry is a process dependent on several factors, such as the type of substrate [1], type of adhesive substance(s) [2], humidity of the environment $[3,4]$, and operator's ability in performing the bonding procedure [5]. With regard to the dental substrates, adhesive procedures are usually performed to achieve bond to dental enamel and dentin. Enamel is a highly-mineralized substrate constituted of almost $100 \mathrm{wt} \%$ of hydroxyapatite crystals, which do not require a wet surface during adhesive procedures for proper bonding. By contrast, dentin is a more complex substrate constituted of both mineral and organic phases (e.g., collagen fibrils), as well as water. Consequently, bonding to dentin is challenging because an ideal moisture condition should be maintained to avoid collapse of the collagen matrix and allow proper adhesive infiltration of the adhesive into the demineralized substrate $[1,6]$.

Dental adhesive systems are commonly characterized by the application of three different substances that fill three distinct clinical steps: etching, priming, and bonding [7]. Etching corresponds to the application of an acid substance to demineralize the surface; priming is the preparation of the etched surface before application of the adhesive, and it is usually applied to dentin alone. Bonding is the application of the hydrophobic resin bond adhesive over enamel and dentin. Acid-etching might be a separate clinical step (etch-and-rinse technique approach [1]), or it might be produced by acidic functional monomers (self-etch materials) [2]. Despite their differences, both techniques have demonstrated long-lasting dental bonding results [1,2].

One of the most recent novelties in adhesive dentistry was the introduction of 'universal' or 'multi-mode' adhesives. These materials are simplified adhesives, usually containing all bonding components in a single bottle. Universal adhesives may be applied either in etch-and-rinse or self-etching bonding approaches, according to manufacturers' claims. In addition, some universal adhesives may contain silane in their formulation, potentially eliminating the silanization step when bonding to glass ceramics or resin composites, for instance. Nevertheless, it is known that simplified materials are associated with lower in vitro bond strength results and poorer in vivo longevity of restorations [8-10]. These findings are probably a result of the complex formulation of simplified adhesives and their high content of solvents, which may impair complete solvent volatilization and consequently lead to poorer adhesive polymerization [11,12].

The aim of this study was to investigate the bonding ability of a universal dental adhesive to different dental substrates (enamel, dentin, composite, and porcelain) in comparison to other contemporary dental bonding agents. The hypothesis tested was that the universal adhesive would have similar bond strength results to the other adhesives irrespective of the substrate tested.

\section{Methods}

\section{Study design}

The design of this in vitro study is shown in Figure 1. Dental substrates (enamel and dentin) and material substrates (resin composite and porcelain) were used to investigate the bond strength performance of distinct bonding agents. The bonding agents tested were: the universal adhesive Scotchbond Universal/SBU (3 M ESPE, St. Paul, MN, USA), the 3-step, etch-and-rinse Scotchbond Multipurpose/SBMP (3 M ESPE), the 2-step, etch-and-rinse 


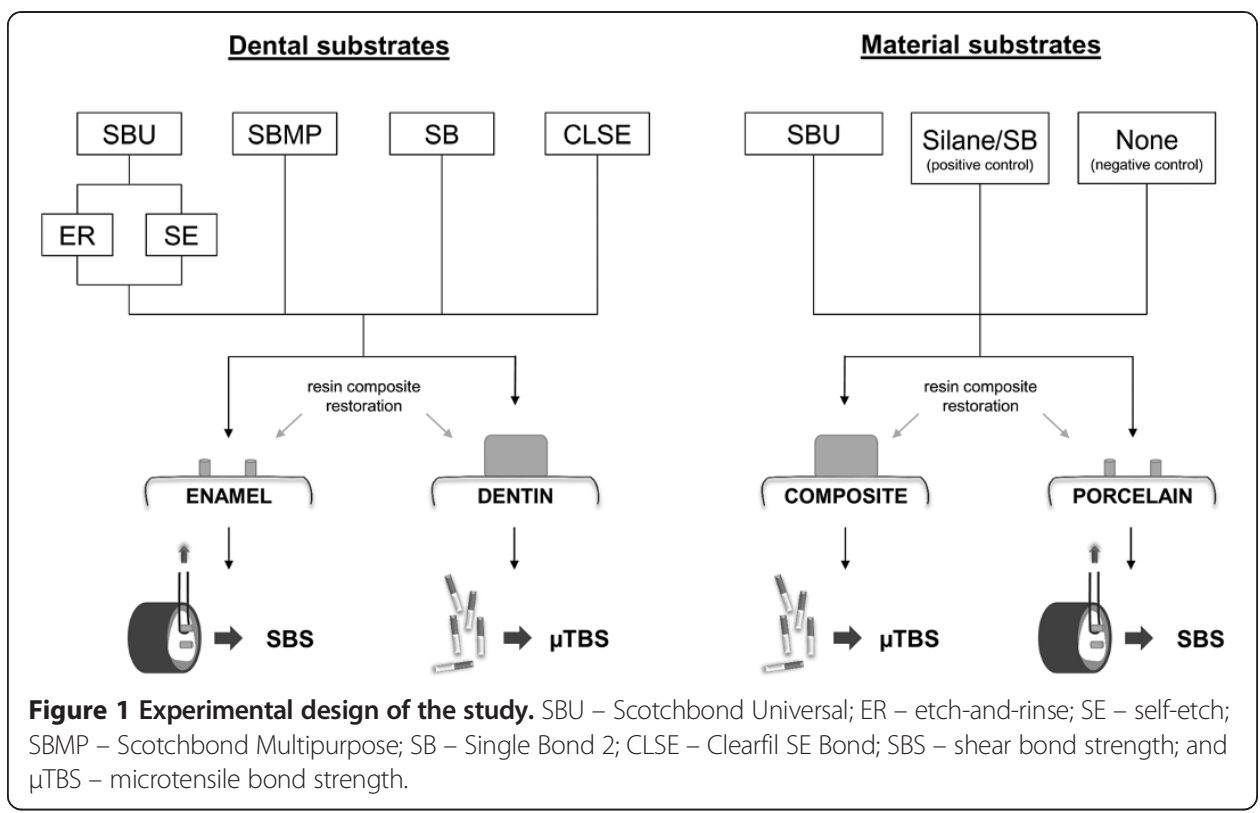

Single Bond 2/SB (3 M ESPE), and the 2-step, self-etch Clearfil SE Bond/CLSE (Kuraray, Osaka, Japan). SBU was tested using both the etch-and-rinse and self-etch bonding approaches. When testing resin composite and porcelain, only SBU was investigated and compared to positive and negative control groups: the positive control was comprised of the application of silane (Silane, Dentsply, York, PA, USA) and SB, whereas the negative control was characterized by no prior treatment of substrates. Information about the $\mathrm{pH}$ (which was measured in triplicate using a pHmeter - Analion, model FM 608, Ribeirão Preto, SP, Brazil), manufacturer, lot number, composition, and directions of application of the bonding agents used are presented in Table 1. The response variables tested were bond strength $(\mathrm{MPa})$ and failure mode, and the number of specimens tested in each group was 20.

\section{Preparation of tooth substrates}

Enamel and dentin specimens were obtained from fifty bovine incisors, which were properly cleaned, disinfected in $0.5 \%$ chloramine-T solution for seven days, and cut to remove the roots. All teeth specimens were randomly allocated into two groups according to the substrate to be tested: enamel or dentin. Enamel specimens were prepared for shear bond strength/SBS testing, i.e., the specimens were embedded in acrylic resin and then wet-ground at the buccal face using 600-grit silicon carbide $(\mathrm{SiC})$ paper in order to standardize the smear layer [1]. Dentin specimens were prepared for microtensile bond strength/ $\mu \mathrm{TBS}$ testing, i.e., the specimens were wet-ground using 600 -grit $\mathrm{SiC}$ paper until exposure of medium dentin. Both enamel and dentin were acid etched with 37\% phosphoric acid (Condac 37; FGM, Joinville, SC, Brazil) for $30 \mathrm{~s}$ and $15 \mathrm{~s}$, respectively and rinsed with water for the same period of the acid-etching. Enamel was completely dried with compressed air, while dentin was kept moist (i.e., neither dry nor wet).

\section{Preparation of resin composite and porcelain}

Fifteen resin composite specimens were prepared by placing a microhybrid composite (Opallis; FGM - shade A3) into a silicone rectangular mold $(18 \times 10 \mathrm{~mm} ; 3 \mathrm{~mm}$ 
Table 1 Information of pH, manufacturer, lot number, composition, and directions of application of the adhesive materials investigated in the study

\begin{tabular}{|c|c|c|c|}
\hline Material $\mathrm{pH}^{\S}$ & $\begin{array}{l}\text { Manufacturer } \\
\text { (Lot number) }\end{array}$ & Composition & Directions of application* \\
\hline $\mathrm{SBU} \mathrm{pH}=2.6^{\mathrm{c}}$ & 3 M ESPE (1302800437) & $\begin{array}{l}\text { MDP phosphate monomer, } \\
\text { dimethacrylate resins, HEMA, } \\
\text { polyalkenoic acid copolymer, } \\
\text { filler, ethanol, water, initiators, } \\
\text { silane }\end{array}$ & $e_{;} c_{i} f(10 s)$ \\
\hline \multirow[t]{2}{*}{$\begin{array}{l}\text { SBMP } \mathrm{pH}=3.9^{\mathrm{b}} \\
\text { (Primer) }\end{array}$} & \multirow[t]{2}{*}{3 M ESPE (205453) } & $\begin{array}{l}\text { Primer: Polyalkenoic acid } \\
\text { copolymer HEMA, water }\end{array}$ & \multirow[t]{2}{*}{$\mathrm{a} ; \mathrm{b} ; \mathrm{c} ; \mathrm{d}(20 \mathrm{~s}) ; \mathrm{c} ; \mathrm{e}(10 \mathrm{~s}) ; \mathrm{f}(10 \mathrm{~s})$} \\
\hline & & $\begin{array}{l}\text { Bond: Bis-GMA, HEMA, tertiary } \\
\text { amines, photo-initiator }\end{array}$ & \\
\hline $\mathbf{S B} \mathrm{pH}=4.2^{\mathrm{a}}$ & 3 M ESPE (330843 BR) & $\begin{array}{l}\text { Dimethacrylate resins, HEMA, } \\
\text { polyalkenoic acid copolymer, } \\
\text { filler, ethanol, water, initiators }\end{array}$ & $\begin{array}{l}\text { a; b; c; e (10 s); c; (repeat 2-3 times } \\
\text { steps "e" and "c" }) ; f(10 \mathrm{~s})\end{array}$ \\
\hline \multirow[t]{2}{*}{ CLSE $p H=1.4^{d}$} & \multirow[t]{2}{*}{ Kuraray (01714-A) } & $\begin{array}{l}\text { Primer: MDP, dimethacrylate } \\
\text { monomer, HEMA, silica, } \\
\text { N,N-diethanol-p-toluidine, CQ }\end{array}$ & \multirow[t]{2}{*}{$d_{;} c_{;} e_{;} c ; f(10 s)$} \\
\hline & & $\begin{array}{l}\text { Bond: HEMA, dimethacrylate } \\
\text { monomer, Bis-GMA, } \\
\text { N,N-diethanol-p-toluidine, } \\
\text { silica, CQ }\end{array}$ & \\
\hline Silane & Dentsply (802197 F) & Silane, ethanol, acetic acid & 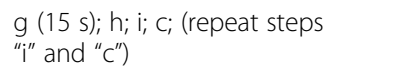 \\
\hline
\end{tabular}

SBU: Scotchbond Universal; SBMP: Scotchbond Multipurpose; SB: Single Bond 2; CLSE: Clearfil SE Bond; MDP: 10-methacryloyloxydecyl dihydrogen phosphate; HEMA: 2-hydroxyethyl methacrylate; Bis-GMA: bisphenol A glycidyl methacrylate; CQ: camphorquinone.

*a: acid-etching (15 s in dentin/resin composite and $30 \mathrm{~s}$ in enamel); b: (rinsing with water for the same period of time of acid-etching); c: drying with compressed air; d: primer application; e: resin bond/adhesive application; f: light-activation; g: mix one drop of the primer and one drop of the activator; $\mathrm{h}$ : let the mixture rest for 5 minutes; i: silane application ${ }^{\S}$ Distinct superscript letters indicate statistically significant differences in $\mathrm{pH}(\mathrm{p}<0.05)$.

thickness) using an incremental technique. Each increment was light-activated for $20 \mathrm{~s}$ with a light-emitting diode (LED) light-curing unit (Radii, SDI, Bayswater, VIC, Australia). The specimens were then prepared for $\mu$ TBS testing following the same procedures described for dentin specimenss.

Fifteen porcelain specimens $(12 \times 10 \mathrm{~mm} ; 2.5 \mathrm{~mm}$ thickness $)$ were obtained from feldspathic porcelain blocks for CAD/CAM (Vitablocks Mark II, Vita Zahnfabrik, Bad Säckingen, Germany). The blocks were cut using a water-cooled diamond saw (Isomet 1000, Buheler Ltd, Lake Bluff, IL, USA) at low speed. The specimens were then prepared for SBS testing following the same protocol described for the preparation of enamel specimens, except for the acid-etching step which was carried out using $10 \%$ hydrofluoric acid for $90 \mathrm{~s}$ (Condac Porcelana, FGM).

\section{Bonding protocol}

The bonding agents were applied according to the manufacturers' directions of application, which are shown in Table 1. Specimens prepared for SBS testing were prepared by inserting resin composite into a silicone mold containing four cylindrical orifices (1.5 $\mathrm{mm}$ in diameter, $0.5 \mathrm{~mm}$ in thickness) followed by light-activation for $20 \mathrm{~s}$. The adhesive was light-activated for $20 \mathrm{~s}$ after positioning the mold onto the surfaces in order to delimitate the bonding area. Specimens prepared for $\mu$ TBS testing were prepared by placing three increments of resin composite over the surfaces and light-activation for 
$20 \mathrm{~s}$ each increment. All specimens were stored in distilled water at $37^{\circ} \mathrm{C}$, for $24 \mathrm{~h}$, and then sectioned in two perpendicular directions to the bonded interface, resulting in beam-shaped specimens with approximately $0.8 \mathrm{~mm}^{2}$ of transverse-sectional area.

\section{Bond strength testing and failure mode analysis}

After storage of all specimens in distilled water, for $24 \mathrm{~h}$, the shear and microtensile bonding tests were carried out using a mechanical testing machine (DL500; São José dos Pinhais, PR, Brazil). While the specimens for SBS test were looped with a thin wire and tested under shear stress, the specimens for $\mu$ TBS test were positioned in a specific jig and then tested under tensile stress [13]. Both SBS and $\mu$ TBS tests were performed at a crosshead speed of $1 \mathrm{~mm} / \mathrm{min}$ until failure, and the bond strength data were calculated in MPa.

After the test, all surfaces were examined using a light stereomicroscope at 40× magnification in an attempt to identify the failure patterns obtained after each bond strength test performed. Failure modes were classified as adhesive, cohesive in the substrate (enamel, dentin, original composite, or porcelain), cohesive in the composite restoration ('fresh composite' for resin composite substrate), or mixed.

\section{Statistical analysis}

The $\mathrm{pH}$ of adhesives as well as the bond strength data were analyzed with the statistical program SigmaPlot version 12 (Systat Software Inc., San Jose, CA, USA) using One-Way Analysis of Variance and Tukey's post hoc test for multiple comparisons $(\alpha=0.05)$.

\section{Results}

\section{$\mathrm{pH}$ of the adhesives}

The $\mathrm{pH}$ of the four adhesives evaluated is shown in Table 1 . The $\mathrm{pH}$ has decreased significantly in the following order: SB > SBMP (Primer) $>$ SBU > CLSE $(\mathrm{p}<0.001)$.

\section{Bond strength to enamel}

The results of bond strength to enamel are presented in Table 2. SB and CLSE resulted in higher bond strength than SBMP ( $\mathrm{p} \leq 0.018$ ), although similar to SBU and regardless of the etching approach used ( $\mathrm{p} \geq 0.458)$. SBU demonstrated similar SBS compared to all other adhesives $(\mathrm{p} \geq 0.145)$.

\section{Bond strength to dentin}

The results of bond strength to dentin are shown in Table 3. SB had the highest bond strength, which was similar to CLSE and SBMP ( $\mathrm{p} \geq 0.848)$ and higher than SBU

Table 2 Shear bond strength means and standard deviation ( \pm SD) for enamel and porcelain

\begin{tabular}{llllllll}
\hline Substrate & SBMP & SB & CLSE & SBU & & Positive & $\begin{array}{l}\text { Negative } \\
\text { control } \\
\text { control }\end{array}$ \\
\hline Enamel & $19.0^{\mathrm{b}}( \pm 10.2)$ & $26.6^{\mathrm{a}}( \pm 9.3)$ & $26.0^{\mathrm{a}}( \pm 8.5)$ & $23.5^{\mathrm{ab}}( \pm 8.4)$ & $22.6^{\mathrm{ab}}( \pm 9.9)$ & & \\
Porcelain & & & & & $29.0^{\mathrm{a}}( \pm 6.9)$ & $21.0^{\mathrm{b}}( \pm 7.0)$ & $5.3^{\mathrm{c}}( \pm 2.7)$ \\
\hline
\end{tabular}

SBMP: Scotchbond Multipurpose; SB: Single Bond 2; CLSE: Clearfil SE Bond; SBU: Scotchbond Universal; SE: self-etch technique; ER: etch-and-rinse technique; Positive control: Silane plus SB; Negative control: no material. Distinct letters in the same row indicate statistically significant differences $(p<0.05)$. 
applied under both ER and SE techniques $(\mathrm{p} \leq 0.045)$. SBU resulted in similar $\mu$ TBS to CLSE and SBMP $(\mathrm{p} \geq 0.123)$.

\section{Bond strength to resin composite}

The results of bond strength to resin composite are displayed in Table 3. SBU and the positive control resulted in similar $\mu$ TBS results $(p=0.963)$, which were higher than the negative control $(\mathrm{p} \leq 0.001)$.

\section{Bond strength to porcelain}

The results of bond strength to porcelain are shown in Table 2. SBU had higher SBS than the positive control $(\mathrm{p} \leq 0.001)$, and both showed higher bond strength than the negative control $(\mathrm{p} \leq 0.001)$.

\section{Failure analysis}

The failure modes results for all bond strength tests performed in the study is shown in Figure 2. In enamel, predominance of adhesive failures was observed in all groups (Figure 2a). In dentin, equilibrium of adhesive and mixed failures was detected (Figure 2b). In resin composite, while the negative control showed only adhesive failures, the positive control and SBU groups presented similar percentages of adhesive and mixed failures (Figure 2c). In porcelain, virtually all failures were adhesive in the negative control and in lower frequency in the other groups (Figure 2d).

\section{Discussion}

The type of substrate is one of the most important factors affecting the bonding performance of adhesives in dentistry [1]. The chemistry of the substrates, that might be dental tissues or restorative materials, may request the application of specific materials to allow a satisfactory and long-lasting bonding. Dentin, for instance, is naturally a complex and wet substrate, requiring the application of both hydrophilic and hydrophobic materials; enamel, on the other hand, requires the application of a hydrophobic material only, since its composition is almost exclusively inorganic [1,2]. In contrast, restorative materials such as resin composites and porcelains have a low reactive structure after curing/sintering, thus requiring the application of specific components to make their surface active again and prone to adhesion [14]. Some universal adhesives present a versatile formulation that may enable adhesion to any type of substrate,

Table 3 Microtensile bond strength means and standard deviation ( \pm SD) for dentin and resin composite

\begin{tabular}{|c|c|c|c|c|c|c|c|}
\hline \multirow[t]{2}{*}{ Substrate } & \multirow[t]{2}{*}{ SBMP } & \multirow[t]{2}{*}{ SB } & \multirow[t]{2}{*}{ CLSE } & \multicolumn{2}{|l|}{ SBU } & \multirow{2}{*}{$\begin{array}{l}\text { Positive } \\
\text { control }\end{array}$} & \multirow{2}{*}{$\begin{array}{l}\text { Negative } \\
\text { control }\end{array}$} \\
\hline & & & & $\overline{\mathrm{SE}}$ & ER & & \\
\hline Dentin & $35.4^{\mathrm{ab}}( \pm 10.5)$ & $39.4^{a}( \pm 11.2)$ & $36.6^{\mathrm{ab}}( \pm 10.9)$ & $28.1^{\mathrm{b}}( \pm 13.7)$ & $26.9^{b}( \pm 7.4)$ & & \\
\hline $\begin{array}{l}\text { Resin } \\
\text { composite }\end{array}$ & & & & & $28.4^{\mathrm{a}}( \pm 9.9)$ & $29.5^{\mathrm{a}}( \pm 11.7)$ & $12.1^{b}( \pm 8.7)$ \\
\hline
\end{tabular}

SBMP: Scotchbond Multipurpose; SB: Single Bond 2; CLSE: Clearfil SE Bond; SBU: Single Bond Universal; SE: self-etch technique; ER: etch-and-rinse technique; Positive control: Silane plus SB; Negative control: no treatment. Distinct letters in the same row indicate statistically significant differences $(p<0.05)$. 


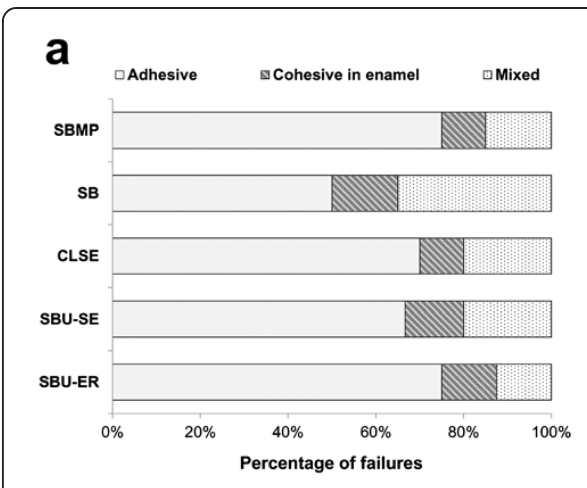

C

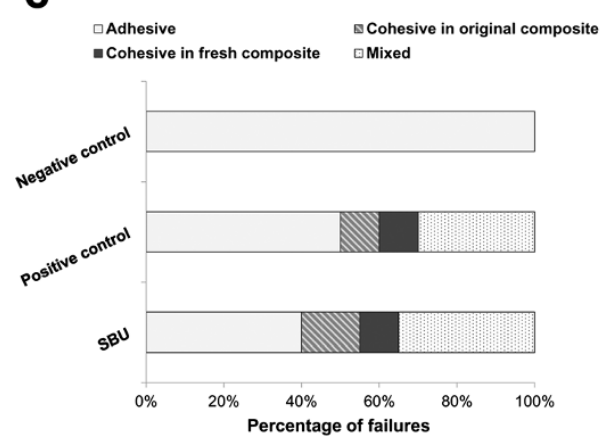

b

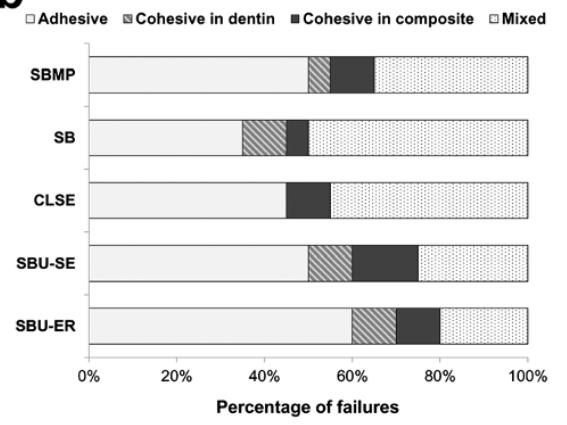

d

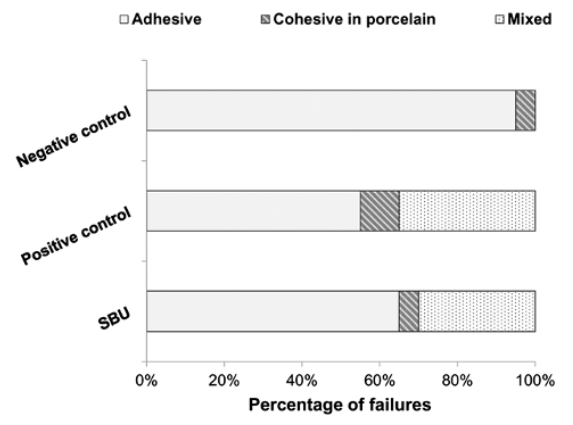

Figure 2 Failure patterns obtained after bond strength evaluation of the adhesive systems applied in enamel (a), dentin (b), resin composite (c), and porcelain (d).

although the performance of universal adhesives tested to different substrates still needs further investigation.

Universal adhesives have the versatility of being applied to dental tissues either using etch-and-rinse/ER or self-etch/SE bonding approaches. Although SE adhesives are easier to apply and commonly less technique-sensitive than ER versions [2], it has been shown that both techniques may lead to appropriates dental bonding [1,2]. Results of the present study corroborate with those previous findings, since groups SBU-SE and SBU-ER had similar enamel and dentin bond strengths. Taking into consideration that the acid-etching with $37 \%$ phosphoric acid was the only difference between the groups, it can be suggested that the application of the acid as a separate clinical step is not essential to improve the bond strength results when using the universal adhesive tested herein. This may be due to the unique composition of SBU (Table 1): first, it is constituted of 10-MDP, which is a phosphate monomer that renders the adhesive an acidic character (in Table 1, SBU and CLSE, which are both 10-MDP-based adhesives, showed the lowest $\mathrm{pH}$ values), enabling simultaneous demineralization and monomer infiltration [2]; second, 10-MDP is a recognized monomer able to chemically interact with tooth minerals [2], improving the longterm stability of the adhesion formed; lastly, SBU is also comprised of a polyalkenoic acid copolymer (Vitrebond ${ }^{\text {Tw }}$ copolymer), which, according to the manufacturer, provides satisfactory bonding to dentin under moist or dry conditions [11].

In enamel, the universal adhesive showed similar bond strength to all the other adhesive systems investigated (Table 2), demonstrating that it would be a good option to promote adhesion between resin composites and enamel. Special attention 
should be addressed to the SBU-SE group, which involved in a single adhesive step of application, differently from the other adhesives. Indeed, the possibility of using an easy and faster bonding agent to satisfactorily bond to enamel and without compromising the adhesion outcome is still important and desired in dentistry [2]. However, it should be highlighted that the selective enamel etching clinical technique is still regarded as the most reliable approach to bond to dental enamel when using self-etch adhesives [15].

In dentin, the bond strength of the universal adhesive was similar to all bonding agents except SB. Considering that dentin is a challenging substrate for adhesion and that the universal SBU is comprised of a heterogeneous composition that mixes various different components into the same solution (e.g., acidic and non-acidic monomers, solvents, fillers, initiators, and silane - Table 1), the combination of these factors may have probably decreased the bonding ability of SBU to dentin. SB, on the other hand, has a less complex composition than SBU, thus allowing satisfactory adhesion, which is corroborated by several previous studies [16-19]. However, this study tested only the immediate bond strength to dentin, and it is known that etch-and-rinse adhesives tend to generate less stable dentin bonding as compared with self-etch adhesives [8].

In resin composite, SBU resulted in similar bond strength when compared to the positive control (i.e., the conventional protocol used to repair resin composite restorations - application of silane and adhesive). In porcelain, SBU showed the highest bond strength, which was higher than the positive control (i.e., application of silane and adhesive) as well as the negative control (no treatment). The repair process of restorative materials such as resin composites and porcelains can be performed by using several chemical substances and physical methods [14,20,21], although the most common procedure performed by dental practitioners is the application of silane prior to the adhesive material. Silane is a coupling agent that interacts with the inorganic glass fillers of resin composites [22]. Consequently, silane is usually applied on the surface of the composites during repairs, for instance. Silane could make the surface of the restorative active again and thus able to adhesively interact with the fresh repairing composite. In a similar fashion, silane is also used for bonding or repairing porcelains, but only after the prior application of hydrofluoric acid, which produces micro-retentions on the surface [23]. In the present study, SBU resulted in higher or similar bond strength when compared to the positive controls, irrespective of the substrate tested. This finding is likely a result of the silane molecule presented in SBU formulation, allowing proper chemical interaction with the glass phases of porcelain and composite.

The present findings demonstrated that the universal dental adhesive tested herein allowed satisfactory adhesion to different substrates of application as compared to the other contemporary agents tested. Findings of the failure analysis corroborate in showing similar performance between the adhesives investigated (Figure 2). It is important to note that SBU performed differently depending on the substrate, thus allowing only the partial acceptance of the study hypothesis. The present study had some limitations, including the immediate $(24 \mathrm{~h})$ testing only and absence of scanning electron microscopy analysis, which would have contributed to the understanding of the quality of the adhesive interfaces. Furthermore, the bonding ability of other universal adhesives on additional substrates (e.g., metals, sclerotic dentin, 
different types of ceramics, among others) still needs evaluation to confirm the universal applicability of these materials.

\section{Conclusion}

The bonding ability of the universal adhesive was comparable to the other contemporary dental bonding agents tested, although it was dependent on the substrate evaluated. Universal adhesives seem to have potential applicability in different areas of the adhesive dentistry.

Competing interests

The authors declare that they have competing interests.

\section{Authors' contributions}

CPI, LLV, and GRB participated in the study design, data collection, data interpretation, manuscript drafting and critical revision. AHP, JKS and AVS participated in the laboratory analyses and data collection. EAM performed the statistical analysis and participated in the data interpretation. RRM participated in the supervision of laboratory research, manuscript drafting, and critical revision. All authors read and approved the final manuscript.

\section{Acknowledgements}

The authors thank FGM Produtos Odontológicos for donation of the composite resin used in the study.

\section{Author details}

${ }^{1}$ Graduate Program of Dentistry, School of Dentistry, Federal University of Pelotas, Rua Gonçalves Chaves, 457, Pelotas RS 96015-560, Brazil. ²Developmental and Control Center of Biomaterials, Federal University of Pelotas, Rua Gonçalves Chaves, 457, Pelotas, RS 96015-560, Brazil.

Received: 24 October 2014 Accepted: 28 November 2014

Published online: 20 December 2014

\section{References}

1. Pashley DH, Tay FR, Breschi L, Tjaderhane L, Carvalho RM, Carrilho M, Tezvergil-Mutluay A (2011) State of the art etch-and-rinse adhesives. Dent Mater 27:1-16

2. Van Meerbeek B, Yoshihara K, Yoshida Y, Mine A, De Munck J, Van Landuyt KL (2011) State of the art of self-etch adhesives. Dent Mater 27:17-28

3. Kanca J 3rd (1997) One step bond strength to enamel and dentin. Am J Dent 10:5-8

4. Münchow EA, Valente LL, Bossardi M, Priebe TC, Zanchi CH, Piva E (2014) Influence of surface moisture condition on the bond strength to dentin of etch-and-rinse adhesive systems. Braz J Oral Sci 13:182-186

5. Giachetti L, Scaminaci Russo D, Bertini F, Pierleoni F, Nieri M (2007) Effect of operator skill in relation to microleakage of total-etch and self-etch bonding systems. J Dent 35:289-293

6. Münchow EA, de Barros GD, Alves LS, Valente LL, Cava SS, Piva E, Ogliari FA (2014) Effect of elastomeric monomers as polymeric matrix of experimental adhesive systems: degree of conversion and bond strength characterization. Appl Adhes Sci 2: doi:10.1186/2196-4351-2-3

7. Alex G (2012) Is total-etch dead? Evidence suggests otherwise. Compend Contin Educ Dent 33:12-14, 16-22, 24-25

8. De Munck J, Van Landuyt K, Peumans M, Poitevin A, Lambrechts P, Braem M, Van Meerbeek B (2005) A critical review of the durability of adhesion to tooth tissue: methods and results. J Dent Res 84:118-132

9. Munoz MA, Sezinando A, Luque-Martinez I, Szesz AL, Reis A, Loguercio AD, Bombarda NH, Perdigao J (2014) Influence of a hydrophobic resin coating on the bonding efficacy of three universal adhesives. J Dent 42:595-602

10. Tuncer D, Yazici AR, Ozgunaltay G, Dayangac B (2013) Clinical evaluation of different adhesives used in the restoration of non-carious cervical lesions: 24-month results. Aust Dent J 58:94-100

11. 3 M ESPE. Scotchbond ${ }^{\mathrm{TM}}$ Universal Adhesive. Date access: November 25, 2014. Available from: http:// multimedia.3m.com/mws/media/7547530/scotchbond-universal-adhesive.pdf?fn=scotchbond_uni_brochure.pdf

12. Spencer $P$, Wang $Y$ (2002) Adhesive phase separation at the dentin interface under wet bonding conditions. J Biomed Mater Res 62:447-456

13. Münchow EA, Bossardi M, Priebe TC, Valente LL, Zanchi CH, Ogliari FA, Piva E (2013) Microtensile versus microshear bond strength between dental adhesives and the dentin substrate. Int J Adhes Adhes 46:95-99

14. Costa TR, Ferreira SQ, Klein-Junior CA, Loguercio AD, Reis A (2010) Durability of surface treatments and intermediate agents used for repair of a polished composite. Oper Dent 35:231-237

15. Peumans M, De Munck J, Van Landuyt KL, Poitevin A, Lambrechts P, Van Meerbeek B (2010) Eight-year clinical evaluation of a 2-step self-etch adhesive with and without selective enamel etching. Dent Mater 26:1176-1184

16. Arrais CA, Giannini M, Nakajima M, Tagami J (2004) Effects of additional and extended acid etching on bonding to caries-affected dentine. Eur J Oral Sci 112:458-464

17. Pereira PN, Nunes MF, Miguez PA, Swift EJ Jr (2006) Bond strengths of a 1-step self-etching system to caries-affected and normal dentin. Oper Dent 31:677-681

18. Singh UP, Tikku A, Chandra A, Loomba K, Boruah LC (2011) Influence of caries detection dye on bond strength of sound and carious affected dentin: An in-vitro study. J Conserv Dent 14:32-35 
19. Yoshiyama M, Urayama A, Kimochi T, Matsuo T, Pashley DH (2000) Comparison of conventional vs self-etching adhesive bonds to caries-affected dentin. Oper Dent 25:163-169

20. Hickel R, Brushaver K, llie N (2013) Repair of restorations-criteria for decision making and clinical recommendations. Dent Mater 29:28-50

21. Valente LL, Münchow EA, Silva MF, Manso IS, Moraes RR (2014) Experimental methacrylate-based primers to improve the repair bond strength of dental composites - a preliminary study. Appl Adhes Sci 2: doi:10.1186/ 2196-4351-2-6

22. Matinlinna JP, Lassila LV, Ozcan M, Yli-Urpo A, Vallittu PK (2004) An introduction to silanes and their clinical applications in dentistry. Int J Prosthod 17:155-164

23. Tian T, Tsoi JK, Matinlinna JP, Burrow MF (2014) Aspects of bonding between resin luting cements and glass ceramic materials. Dent Mater 30:e147-e162

doi:10.1186/s40563-014-0025-x

Cite this article as: Isolan et al:: Bond strength of a universal bonding agent and other contemporary dental adhesives applied on enamel, dentin, composite, and porcelain. Applied Adhesion Science 2014 2:25.

Submit your manuscript to a SpringerOpen ${ }^{\circ}$ journal and benefit from:

- Convenient online submission

- Rigorous peer review

- Immediate publication on acceptance

- Open access: articles freely available online

- High visibility within the field

- Retaining the copyright to your article

Submit your next manuscript at $>$ springeropen.com 